\title{
A PECUÁRIA LEITEIRA E A AGRICULTURA FAMILIAR EM ITUIUTABA (MG): AS TRANSFORMAÇÕES NA COMUNIDADE DA CANOA ${ }^{1}$
}

\section{DAIRY PRODUCTION AND FAMILY FARMING IN ITUIUTABA (MG): THE CHANGES AT CANOA COMMUNITY}

\author{
Wanderléia Aparecida de Oliveira Gobbi \\ Licenciada / Bacharela e Mestre em Geografia pelo Instituto de Geografia da \\ UFU \\ E-mail:wogobbi@gmail.com \\ Vera Lúcia Salazar Pessôa \\ Prof $^{a}$. Dra . do Programa de Pós-graduação em Geografia da UFU \\ E-mail:vspessoa98@yahoo.com.br
}

RESUMO: Este trabalho teve como objetivo a realização de um estudo sobre a pecuária leiteira no contexto da agricultura familiar, levando em conta as transformações recentes no município de Ituiutaba (MG). O município está localizado na porção noroeste da Mesorregião do Triângulo Mineiro/Alto Paranaíba. Essa região não ficou fora do processo de modernização da agricultura que ocorreu no país, a partir da década de 1960.

Palavras-Chave: pecuária leiteira, agricultura familiar, Ituiutaba (MG), Comunidade da Canoa.

ABSTRACT: This paper intends to study the dairy production in a family farmer context. The study was realized in Ituiutaba county, in the northest of Triângulo Mineiro/Alto Paranaíba geographic region. This region has been included in the modernization process that took place in Brazil since 1960.

Keywords: dairy production, family farming, Ituiutaba (MG), Canoa Community.

\section{INTRODUÇÃO}

A pecuária é uma atividade de grande relevância no município de Ituiutaba (MG), sendo que a produção de leite é um segmento que se destaca, devido ao seu caráter de complementaridade à renda dos pequenos produtores familiares. A produção de leite, via de regra, não é especializada, porém é 
praticada por produtores que estão incorporando, progressivamente, tecnologia ao processo produtivo, haja vista a utilização de tanques de expansão e ordenhadeiras mecânicas. Cabe ressaltar que uma parcela considerável dos produtores mantém vínculos com o comércio informal de leite e derivados para complementação da renda e melhores preços.

Nesse contexto, o trabalho busca incorporar um estudo de caso realizado na Comunidade da Canoa, a uma realidade mais ampla e complexa, visto que se considera que os locais integram-se à economia global, por intermédio dos mercados, das relações de compra e venda. A Comunidade da Canoa dista, aproximadamente, $42 \mathrm{~km}$ da sede municipal.

Assim, este trabalho teve por objetivo compreender a pecuária leiteira no contexto da agricultura familiar, levando em conta as transformações recentes em Ituiutaba (MG). O município escolhido para estudo localiza-se na porção noroeste da Mesorregião do Triângulo Mineiro/Alto Paranaíba (Mapa 1). Essa região não ficou fora do processo de modernização da agricultura que ocorreu no país, a partir da década de 1960.

O texto está estruturado, além da introdução e considerações finais, em dois itens. No primeiro item, situamos a pecuária leiteira no contexto da agricultura familiar. Para tanto, retomamos a discussão sobre a agricultura familiar no Brasil, desde a formação da pequena produção até a importância da agricultura familiar no pós 1990. No segundo item, mostramos a importância da agricultura familiar e da pecuária leiteira em Ituiutaba (MG). 


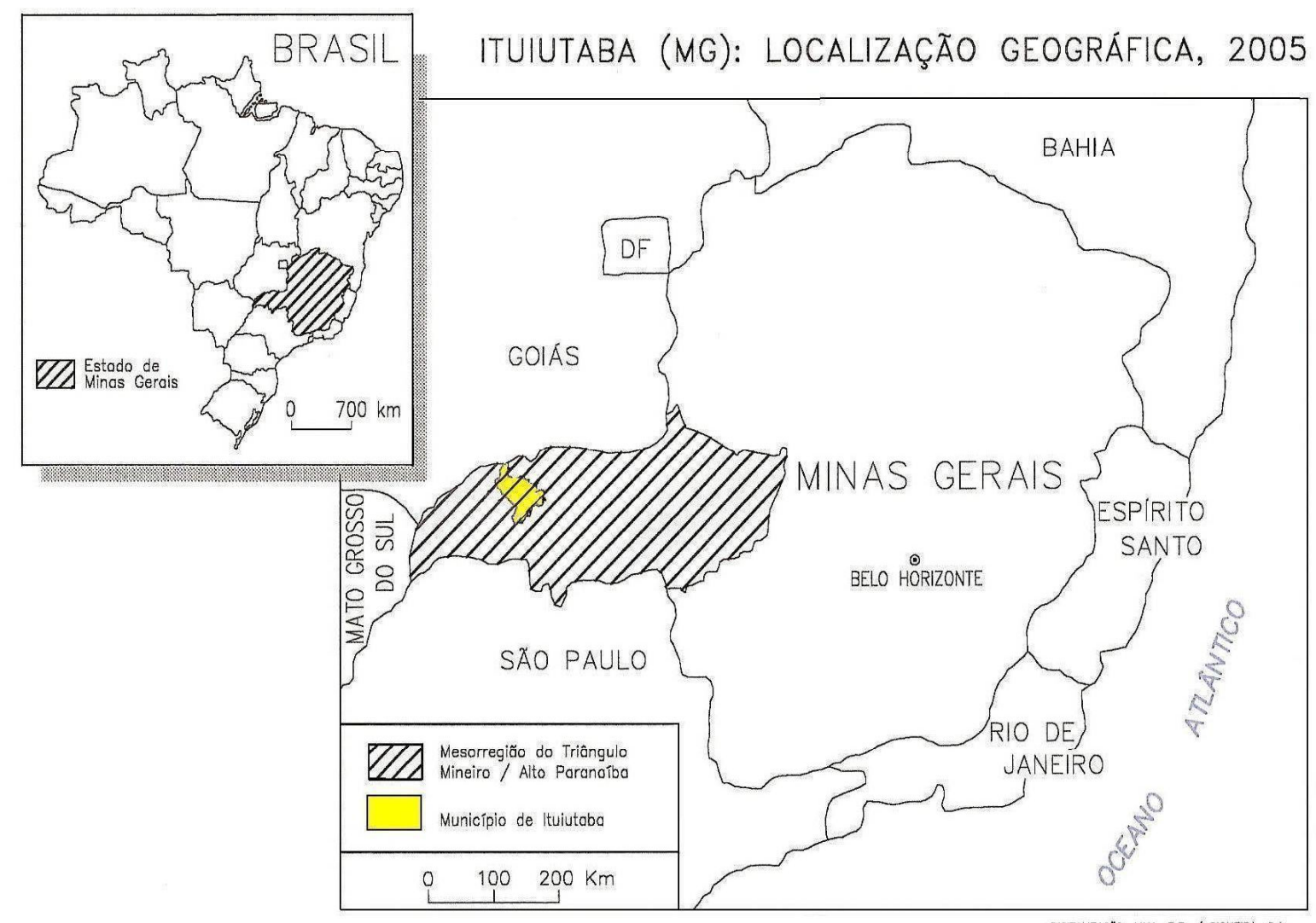

DIGITLLZAGGAO: LIMA, E.F. / SIQUEIRA, C.A

A agricultura familiar no Brasil: retomando a discussão

\section{A formação da pequena propriedade no Brasil}

O surgimento da pequena exploração agrícola no contexto de desenvolvimento do capitalismo, no meio rural brasileiro, tem raízes e especificidades históricas, com destaque para dois momentos cruciais, quais sejam: o período colonial, com o advento da grande exploração; e o transcorrer do século XIX, com a criação de núcleos coloniais com base na pequena propriedade rural.

No período colonial, a economia estava, de acordo com Prado Júnior (1981), baseada na grande exploração, uma vez que essa organização fundiária atendia aos interesses da metrópole portuguesa e do próprio sentido da colonização do país, que, na perspectiva desse autor, estava centrada no empreendimento comercial.

Na análise de Prado Júnior (1981), a grande exploração representou o "nervo" da agricultura colonial, em detrimento da pequena, que, nesse período, 
representava um apêndice da organização agrária de grande porte econômico, possuindo, dessa forma, um caráter de economia complementar e subsidiária.

Os principais elementos de sustentação da grande lavoura, como é o caso do trabalho escravo e da monocultura, propiciaram, até o século XIX, uma considerável expansão em termos econômicos. Porém, com a abertura política e econômica de 1808 e, sobretudo, com a transição para o trabalho livre (segunda metade do século XIX), tais elementos mostraram-se amplamente desfavoráveis. Foi nesse contexto que se consolidou, no Brasil, o papel da pequena propriedade agrícola.

A pequena propriedade, no Brasil, possui características e particularidades, com relação ao seu surgimento e consolidação, em diferentes regiões do país. Isso porque, diferentemente do que ocorreu no sul do Brasil, onde se originou mediante políticas de criação de núcleos coloniais, no Estado de São Paulo, a pequena propriedade surgiu como forma de atrair mão-de-obra imigrante à lavoura cafeeira.

A partir da criação desses núcleos coloniais, muitos colonos passaram a ser atraídos pela possibilidade de se transformarem em pequenos proprietários de terra. Para Petrone (1982, p.48), as propostas do governo atendiam aos interesses desses imigrantes:

em São Paulo, a pequena propriedade surgiu com objetivos diferentes do que nos outros estados e se integrou em realidade outra, transformando-se em elemento complementar do latifúndio.

O aceno de acesso à terra depois de um estágio na fazenda fazia dos projetos de criação de pequena propriedade uma "isca" para atrair imigrantes.

Conforme apontou Petrone (1982), os núcleos coloniais, diferentemente da Região Sul, em São Paulo, não prosperaram, tanto em número quanto em eficácia de povoamento, e, no caso específico de São Paulo, predominou a 'imigração subvencionada', que empregava os braços dos imigrantes à grande lavoura cafeeira.

A partir de 1840, com a progressiva expansão do café no estado de São Paulo e, sobretudo, com a falta de braços à lavoura em virtude da transição ao trabalho livre, criou-se um embate com relação ao destino dos colonos 
imigrantes. Isso porque eles passaram a ser disputados tanto por núcleos de pequena propriedade, como também pelos fazendeiros de café em São Paulo:

[...] a pequena propriedade em São Paulo devia funcionar como reservatório de braços com os quais o fazendeiro podia contar por ocasião da colheita. E esse aspecto que induziu muitos fazendeiros a lotear, em seus domínios ou nos seus limites, as terras não próprias para a cultura de café, a fim de fixar próximo ao cafezal uma população que, para arredondar seus rendimentos, ofereceria sua força de trabalho em certas ocasiões. (PETRONE, 1982, p. 48).

Assim, o surgimento da pequena propriedade, em São Paulo, no século XIX, cumpriu outros objetivos e transformou-se num elemento complementar ao latifúndio, em contraste com outras áreas, cujos objetivos militares de ocupação com base na pequena propriedade conseguiram êxito, embora muitos núcleos tenham ficado isolados no âmbito econômico.

Petrone (1982) lembra-nos que uma das formas de implementar a entrada de imigrantes nas fazendas de café no Estado de São Paulo foi o contrato de trabalho. Nesse sentido, o sucesso atingido pelo sistema de parceria nas fazendas de café possibilitou, de certa forma, o crescimento da produção, assim como das áreas plantadas com essa cultura em direção a outras áreas do estado de São Paulo.

Foi com o advento da cultura do café e, sobretudo, a partir da Lei Euzébio de Queiroz (1850), que teve início o processo de passagem do trabalho escravo ao sistema de colonato com base no trabalho imigrante, que, por sua vez, consolidou a importância do trabalho familiar assentado na pequena propriedade. Entretanto, foi como complemento do latifúndio que a pequena propriedade instalou-se como parte do processo fundiário no meio rural.

\section{A modernização agrícola e o pequeno produtor}

O desenvolvimento da agricultura, ocorrido no Brasil no período entre 1930 e 1960, foi marcado por um padrão de crescimento agrícola, apoiado na 
expansão horizontal com baixo nível tecnológico e pela ação do Estado por meio de políticas de colonização, para o crescimento da economia agrícola, voltando a produção para o mercado interno (SORJ, 1986).

Portanto, a dinâmica da produção agrícola tinha passado a orientar-se por determinantes internos. Com o deslocamento da produção para o mercado interno, as transformações da base técnica ainda estavam vinculadas ao setor externo, dependendo da capacidade de importação de máquinas e insumos que o país tinha, para que houvesse a incorporação de inovações técnicas. Assim, as decisões de produzir estavam se internalizando gradativamente, dadas as novas exigências do mercado nacional, enquanto os elementos necessários à produção dependiam cada vez mais da abertura para o mercado externo (KAGEYAMA, 1990).

Ocorreu um intenso processo de modernização das atividades agrícolas com base na revolução verde, que beneficiou principalmente as grandes propriedades, que exploravam produtos para exportação e se localizavam, em grande parte, nas regiões mais industrializadas do país. Apesar das grandes modificações introduzidas na estrutura produtiva do campo, o padrão de distribuição fundiária preservou sua principal característica, a forte concentração de terras. Os pequenos produtores rurais, em sua maioria, não se beneficiaram com o crescimento ocorrido nesse período (WANDERLEY, 1997).

As principais instituições que lidavam com as questões agrícolas governamentais, de ensino, de pesquisa, de assistência técnica pautavam-se pelo modelo da revolução verde, que priorizava o incremento da produção e da produtividade mediante a incorporação de tecnologias agroquímicas e mecânicas. O planejamento das ações orientadas para o desenvolvimento rural centrava-se nas atividades desenvolvidas no interior das unidades produtivas, não considerando, adequadamente, os processos que se realizavam à sua montante e jusante, o que, inevitavelmente, gerava uma visão reducionista e distorcida do setor agrícola (GRAZIANO DA SILVA, 1999). Por outro lado, a intervenção do Estado orientava-se, em grande parte, por princípios 
patrimonialistas, na alocação dos recursos públicos no setor, o que ampliava as desigualdades existentes.

A maneira de compreender e de intervir no campo, se, de um lado, contribuiu para a emergência dos grandes complexos agroindustriais, de outro, manteve os acentuados níveis de pobreza que atingiam a maioria da população rural (PEIXOTO, 1998). Dito de outra maneira, o processo de crescimento da agricultura criou novas realidades produtivas, mas não foi capaz de resolver as principais questões sociais existentes.

Portanto, o dinamismo atual das atividades agrícolas precisa ser compreendido em novas bases teóricas, incorporando as determinações geradas pela globalização e pela abertura da economia para o exterior, mas as questões herdadas do passado também requerem um entendimento baseado em um quadro de referências novas, por sua vez, condicionado pelo aparecimento de um novo contexto social.

A crescente internacionalização e interligação dos mercados gerou a necessidade de novos padrões de qualidade para os bens produzidos, a preocupação com a conservação dos recursos materiais e com a autosustentabilidade da produção agrícola. Por outro lado, o aprofundamento das relações intra e intersetoriais fez com que a agricultura deixasse de ser vista como uma atividade setorial e, sim, como uma cadeia produtiva.

Por essa ótica, as determinações mais importantes da produção agrícola estão situadas fora dela e não mais no seu interior. As cadeias produtivas compreendem os processos que se dão à montante da propriedade (crédito, insumos, maquinário etc.), os que ocorrem em nível da produção agrícola e os que se efetivam à sua jusante, a exemplo da industrialização e comercialização dos produtos obtidos. Estes últimos implicam uma contínua agregação de valor aos bens produzidos. Isto vai configurar o que, na literatura recente, é denominado de "negócio agrícola", cujo elo mais importante são, justamente, os grandes complexos agroindustriais, que passam a responder pela maior parte do valor da produção agrícola (PEIXOTO, 1998).

Embora, hoje (2005), a modernização da agricultura atinja, direta ou indiretamente, todo o país, processou-se de forma extremamente seletiva, 
privilegiando os territórios, as culturas e os segmentos socioeconômicos mais rapidamente suscetíveis à organização de uma atividade agrícola sustentada pelas inovações científico-técnicas e que, assim, pudessem ter uma produção e um consumo globalizados e interligados aos demais setores econômicos. A difusão de inovações, assim como a distribuição de crédito rural deram-se de maneira não uniforme, constituindo um setor baseado em uma estrutura dual, promovendo um desenvolvimento cada vez mais desigual e combinado do setor no país. As áreas, as culturas e os produtores que não foram, de alguma forma, incorporados ao processo de modernização exercem papéis periféricos na organização da produção agrícola que se processa nas últimas décadas. 0 espaço rural não foi homogeinizado, uma vez que foi desigualmente atingido pela difusão de inovações agrícolas. Construiu-se, desse modo, um espaço seletivo, com uma forte concentração territorial das formas resultantes do processo de modernização da agricultura.

Enquanto o modelo tradicional de exportação de produtos agropecuários era baseado, particularmente, na utilização extensiva de terra e da força de trabalho, o modelo ideal do período da modernização teve como fundamento o uso intensivo de capital, tecnologia, informação, mão-de-obra especializada e uma quantidade incomensurável de insumos industrializados diversos, o que acabou por desenvolver diversos ramos da indústria. Paralelamente à modernização da agricultura, desenvolveu-se um moderno parque industrial, fosse das indústrias para suprir as novas demandas da atividade agrícola e pecuária (fertilizantes, adubos, tratores, pulverizadores, etc), fosse das indústrias para transformar os resultados dessa produção das agroindústrias.

Nas áreas agrícolas onde o desenvolvimento ocorreu de forma integrada aos demais setores econômicos e em bases modernas, foi comum o processo de substituição das culturas voltadas à demanda do mercado interno de alimentos (como o arroz, o feijão, o milho, a mandioca, a batata, a cebola, entre outros), pelas culturas voltadas à exportação (soja, cana-de-açúcar e laranja), com preços mais competitivos no mercado internacional. Estas últimas passaram a ocupar parte significativa da pauta de exportações do Brasil, nas décadas mais recentes $(1990,2000)$ e caracterizam-se por serem produzidas 
em grandes propriedades, por terem amplo acesso ao capital financeiro e às inovações, por contarem com um sistema de transporte e armazenamento modernos e por todas as demais influências da produção agrícola brasileira moderna.

Em contrapartida, a produção e a produtividade dos alimentos voltados à demanda do mercado interno modernizaram-se muito menos, crescendo em ritmo mais lento e, muitas vezes, até decrescente, gerando escassez e obrigando, em vários casos, a importação de produtos tradicionalmente pertencentes à cesta básica do brasileiro, como o feijão, o arroz, a carne bovina, o leite, que se tornaram mais onerosos no orçamento da maior parte da população.

\section{A agricultura familiar: a revalorização no pós 1990}

A agricultura familiar brasileira foi marcada profundamente pelas origens coloniais da economia e da sociedade brasileira, com suas três grandes características: a grande propriedade, as monoculturas de exportação e a escravatura. A fragilidade e a dependência social e política desse estrato de agricultores estão estreitamente relacionadas com os eventos que proporcionaram o surgimento das grandes propriedades, a partir de 1850, e com os "ciclos" econômicos do açúcar e café.

No período das monoculturas exportadoras, como a determinação do volume a ser produzido estava diretamente ligada ao preço internacional, estando este em alta, estimulava-se a expansão dos produtos familiares para o abastecimento do mercado interno, pois as terras dos latifúndios eram utilizadas exclusivamente para a produção de exportação. Com a queda dos preços internacionais, parte das terras ocupadas com a monocultura era trabalhada pelos escravos ou arrendatários para a produção de subsistência e para o suprimento do mercado interno.

Portanto, "no início do século XIX, a extinção do regime de sesmarias, aliada à ausência de outra legislação regulando a posse das terras devolutas, provoca uma rápida expansão dos sítios desses pequenos produtores" 
(GRAZIANO DA SILVA,1996, p. 27). Assim, com a implantação da Lei de Terras, em 1850, cria-se um instrumento de restrição ao acesso à terra, podendo adquiri-la somente o proprietário de capital. Aliada a esse fato, ocorre a proibição do tráfico negreiro e, em 1888, a abolição da escravatura.

O resultado dessas medidas foi a criação da força de trabalho nãoescrava, formada por homens sem condição de ter acesso à terra, que vinham somar-se ao contingente, já existente, de homens livres desprovidos de capital. Formou-se uma grande massa de mão-de-obra disponível, atendendo às necessidades dos latifúndios que, além de verem supridas suas necessidades de trabalhadores, ficariam protegidos contra uma expansão da propriedade familiar, pois "[...] se houvesse homem 'livre' com terra 'livre', ninguém iria ser trabalhador dos latifúndios" (GRAZIANO DA SILVA,1996, p. 28).

Após 1888, verificamos a instalação de uma indústria no país, ainda que incipiente: fabricas de chapéus, de louças, de fiação e tecelagem, gerando um novo campo para a propriedade familiar, que, a partir daí, poderia produzir, além de alimentos, matérias-primas para essas fábricas, "[...] uma vez que o latifúndio continua a monopolizar a produção destinada à exportação - o café" (GRAZIANO DA SILVA,1996, p. 29).

Por volta de 1930, ocorreu a crise do café e o início da efetiva industrialização do país. O núcleo da economia foi, lentamente, sendo transferido da agricultura para a indústria. Nesse processo, a indústria ia, progressivamente, assumindo a liderança do processo de acumulação de capital. Entretanto, o deslocamento do foco da economia no sentido agricultura/indústria, alavancado pelo capital das oligarquias cafeeiras, não resultou em uma alteração na estrutura agrária do país.

O início da modernização da agricultura deu-se somente após a metade dos anos de 1950 e trouxe para o Brasil as indústrias de tratores e equipamentos agrícolas, fertilizantes químicos, rações e medicamentos veterinários, dentre outros.

A partir da constituição desses novos ramos da indústria agrícola, novos mercados também tinham que se abrir. O governo implementou um conjunto de políticas agrícolas destinadas a incentivar a aquisição dos produtos desse 
novo ramo da indústria, acelerando o processo de incorporação de modernas tecnologias pelos produtores rurais.

Esse modelo desenvolvimentista gerou uma grande concentração de terras e de renda no meio rural, marginalizando, do processo, mais de dois terços da população que vivia no campo (www.seag.es.gov.br, 2005).

O resultado desse modelo tem-se refletido, de maneira geral, apesar do aumento na produção global, no agravamento do desemprego no campo e na cidade, no aumento dos preços dos alimentos, na degradação do meio ambiente e na ocupação desordenada do território nacional. Outros problemas estão também vinculados ao modelo, como a queda na qualidade dos alimentos e o progressivo desaparecimento das tradições culturais no meio rural.

Assim, numa perspectiva histórica, pode-se observar que as características que marcaram a agricultura brasileira foram: "[...] de um lado, grande sucesso comercial das culturas de exportação e, de outro, escassez relativa de gêneros alimentícios, exploração predatória da natureza, escravização da mão-de-obra seguida de precárias condições de acesso à terra e de emprego" (ROMEIRO, 1998, p. 101).

A partir da década de 1990, a discussão sobre agricultura familiar vem tomando força no Brasil devido ao reconhecimento da importância desse segmento econômico em gerar renda, emprego e melhores condições de vida no campo. As abordagens dos autores, a seguir, possibilitam melhor compreensão dessa realidade.

Wanderley (1999) mostra que a agricultura familiar é uma categoria genérica, que tem como característica uma vasta diversidade de formas sociais. Dentre estas diversas formas sociais que compõem a agricultura familiar, podemos destacar a agricultura camponesa, a agricultura de subsistência e a pequena produção. Por isso, é importante fazer distinções, que, por vezes, causam algumas distorções conceituais. Uma dessas distinções é diferenciar agricultura camponesa de agricultura de subsistência:

[...] conforme os objetivos que se propõem os agricultores, para si mesmos e para suas famílias, e conforme, 
também, os contextos sócio-econômicos (sic) locais e o respectivo nível de desenvolvimento, deve-se distinguir as unidades de produção camponesas de outras consideradas de subsistência. Se a função de subsistência está bem presente no modelo camponês, ele não se reduz jamais a isto; há neste modelo, profundamente arraigada, uma vontade de conservação e de crescimento do patrimônio familiar. (WANDERLEY, 1999, p. 30).

A outra distinção importante a fazer é entre agricultura camponesa e pequena produção:

[...] a agricultura camponesa é, em geral, pequena; dispõe de poucos recursos e tem restrições para potencializar suas forças produtivas; porém, ela não é camponesa por ser pequena, isto é, não é sua dimensão que determina sua natureza, e, sim, suas relações internas e externas [...]. (WANDERLEY, 1999, p. 31).

Ainda sobre o conceito de agricultura familiar, Wanderley (1999) e Abramovay (2000) destacam que ela é centrada na propriedade dos meios de produção e na execução do trabalho por familiares.

Retomando as idéias de Wanderley (1999), a autora mostra que é necessário, para a compreensão dessas diversas formas sociais, o conhecimento do conceito de agricultura familiar, ou seja, "aquela em que a família, ao mesmo tempo em que é proprietária dos meios de produção, assume o trabalho no estabelecimento produtivo" (WANDERLEY, 1999, p. 23).

As opiniões sobre a agricultura camponesa não são muito divergentes, pois, para Wanderley (1999) e Abramovay (2000), a produção, nessa categoria, não possui fins lucrativos, mas para a subsistência.

A agricultura camponesa é considerada por Wanderley (1999) como uma das formas sociais que compõem a agricultura familiar, pois ela é baseada na relação entre propriedade, trabalho e família, porém apresenta algumas características no que tange à sua inserção no meio econômico e social.

Para Abramovay (2000), a atividade econômica, dentro da agricultura camponesa, é determinada pelas necessidades de consumo do grupo, ou seja, o volume de trabalho é determinado pelo consumo familiar. Assim, 
diferentemente de uma empresa capitalista, num estabelecimento camponês o critério de maximização da utilidade não é a obtenção da maior lucratividade possível em determinadas condições. O uso do trabalho camponês é limitado pelo objetivo fundamental de satisfazer às necessidades familiares. (ABRAMOVAY, 2000, p.61).

É nessa caracterização do trabalho camponês que Abramovay (2000) mostra o conceito de auto-exploração do campesinato desenvolvido por Chayanov, que assim se refere: "[...] mientras el tamaño de la unidad agraria capitalista es teóricamente ilimitada, la extensión de la unidad doméstica de explotación agraria está naturalmente determinada por la relación entre las necesidades de consumo de la familia y su fuerza de trabajo" (CHAYANOV, 1974, p. 89).

$\mathrm{Na}$ luta para garantir a sua reprodução social, a agricultura camponesa promove investimentos em busca de melhores condições de vida ou, pelo menos, manutenção das condições atuais para as gerações futuras.

[...] um dos eixos centrais da associação camponesa entre família, produção e trabalho é a expectativa de que todo investimento em recursos materiais e de trabalho despendidos na unidade de produção, pela geração atual, possa vir a ser transmitido à geração seguinte, garantindo a esta, as condições de sua sobrevivência. (WANDERLEY, 1999, p. 3).

Lamarche (1998, p. 70) apresenta claramente o conceito do modelo de agricultura camponesa:

este modelo define-se por uma forte predominância das lógicas familiares e uma fraca dependência em relação ao exterior. Composto por estabelecimentos que produzem pouco e utilizam técnicas bastante tradicionais, o objetivo primeiro aqui é satisfazer às necessidades familiares.

Para Lamarche (1998), a existência de modelos de agricultura camponesa ou de subsistência em contextos socioeconômicos específicos pode ser justificada por estarem num estágio de subdesenvolvimento das atividades ou por uma crise de desenvolvimento. 
Outra discussão sobre a agricultura familiar foi aquela apresentada pelo Relatório INCRA/FAO (1996). O Relatório, utilizando dados do Censo Agropecuário 1995/96, adotou os seguintes critérios:

[...] a) a direção dos trabalhadores era exercida pelo produtor; b) não foram realizadas despesas com serviços de empreitada; c) sem empregado permanentes e com número médio de empregados temporários menor ou igual a três; d) com área total menor ou igual a quinhentos hectares para as regiões Sudeste e Sul, mil hectares para as demais regiões. (INCRA/FAO, 1996, p. 5).

Portanto, o relatório, elaborado pelo estudo INCRA/FAO (1996), deixa claro que o tamanho da propriedade é determinado pelo que a família pode explorar com base em seu próprio trabalho, associando-o à tecnologia de que dispõe ${ }^{2}$.

A importância dos agricultores familiares é também mostrada no Projeto de Cooperação Técnica INCRA/FAO (2000), que utilizou dados do Censo Agropecuário 1995/96: os agricultores familiares são responsáveis por 30,5\% da área total cultivada no país, correspondendo a $85,2 \%$ de estabelecimentos e contribuindo com $37,9 \%$ da produção total. Ainda de acordo com o estudo, os agricultores familiares demonstram ser mais eficientes no uso do crédito rural que os agricultores patronais, pois produzem mais com menos recursos do crédito rural.

Após essa breve apresentação do conceito de agricultura familiar, é necessário conhecer o contexto nacional em que esse segmento da agricultura se insere no Brasil. Para isso, é necessário compreender sua participação no desenvolvimento agrícola brasileiro e na produção familiar.

De acordo com a tabela 1, o total de estabelecimentos familiares é de 4.139.369, sendo que, deste total, a maioria encontra-se localizada na região Nordeste (2 milhões), seguida pela região Sul (907 mil), região Sudeste (633 mil), região Norte $(380$ mil) e a região Centro-Oeste com 162 mil estabelecimentos familiares.

Tabela 1 - Número de estabelecimentos familiares e participação relativa das grandes regiões brasileiras - 1995/96 


\begin{tabular}{l|c|c|c|c}
\hline Regiões & $\begin{array}{c}\mathbf{N} .^{\circ} \text { de } \\
\text { Estabelecimentos } \\
\text { Total }\end{array}$ & $\begin{array}{c}\mathbf{N} .^{\circ} \text { de } \\
\text { Estabelecimentos } \\
\text { Familiares }\end{array}$ & $\begin{array}{c}\% \text { sobre o } \\
\text { Total } \\
\text { Nacional } \\
\text { Familiar }\end{array}$ & $\begin{array}{c}\% \text { sobre } \\
\text { o Total } \\
\text { Regional }\end{array}$ \\
\hline Norte & 446.175 & 380.895 & 9,2 & 85,4 \\
\hline Nordeste & 2.326 .413 & 2.055 .157 & 49,7 & 88,3 \\
\hline Sudeste & 841.665 & 633.620 & 15,3 & 75,3 \\
\hline Sul & 1.003 .179 & 907.635 & 21,9 & 90,5 \\
\hline $\begin{array}{l}\text { Centro- } \\
\text { Oeste }\end{array}$ & 242.436 & 162.062 & 3,9 & 66,8 \\
\hline BRASIL & $\mathbf{4 . 8 5 9 . 8 6 8}$ & $\mathbf{4 . 1 3 9 . 3 6 9}$ & $\mathbf{1 0 0 , 0}$ & $\mathbf{8 5 , 2}$ \\
\hline
\end{tabular}

Fonte: IBGE - Censo Agropecuário (MG) 1995/96. Disponível em: INCRA/FAO $<$ http://www.incra.gov.br/sade/EstabArea vBPFAM. asp>. Acesso em: 23 jun. 2005.

Org. GOBBI, W. A. de O. /2005

Assim, podemos verificar que a região Centro-Oeste (Tabela1) ocupa a menor percentagem de propriedades familiares tanto em termos de total nacional $(3,9 \%)$ como no total regional $(66,8 \%)$. Para Caume (1997, p. 12$)$, a justificativa se dá "pelas características do seu processo de ocupação histórica alicerçado em grandes unidades praticantes de uma pecuária de caráter extensivo." Pessoa (1999) afirma que essa atividade era a mais viável economicamente para a região, por exigir apenas pastagens naturais, pouca mão-de-obra, instalações rústicas e reduzido capital.

A região Nordeste compreende $49,7 \%$ de propriedades familiares (total nacional). Para Azevedo (2005, p.1), a predominância da propriedade familiar nessa região ocorre porque,

no Nordeste, a pecuária deu sustentação tanto à plantation açucareira quanto à cotonicultura, persistindo e ganhando força nas décadas atuais, pós-falência cotonícola. A partir das transformações econômicas e socioespaciais ocorridas durante a formação histórica nordestina, a pecuária partiu de uma base estritamente de corte para a consolidação da produção de leite. Não obstante os fatores limitantes como condições naturais desfavoráveis e volubilidade do mercado, a mesma tem ganhado força, se modernizando e se expandindo, graças ao incentivo estatal. 
A região Sul participa com o segundo maior número de produtores familiares (907 mil), porém trata-se de uma região colonizada por emigrantes europeus, que trouxeram o modelo de produção de seus países de origem, e onde a modernização da agricultura teve maior alcance que a ocorrida no Nordeste. Essa região também se caracteriza por grande difusão do cooperativismo e do associativismo e maiores facilidades para captar recursos governamentais. Já a região Sudeste se encontra no patamar intermediário, abrangendo, respectivamente, $15,3 \%$ do total nacional e $75,3 \%$ do total regional.

Conforme tabela 2, no Brasil, $39,8 \%$ dos estabelecimentos familiares atingem, sob qualquer condição, menos de 50 ha, sendo que outros $30 \%$ possuem entre 5 e 20 ha, e $17 \%$, entre 20 e 50 ha. Ou seja, $87 \%$ dos estabelecimentos familiares abrangem menos de 50 ha. Os agricultores familiares com área maior que 100 ha e menor que a área máxima regional são representados por $5,9 \%$ dos estabelecimentos, mas ocupam $44,7 \%$ de toda a área da agricultura familiar brasileira.

Tabela 2 - Brasil - agricultura familiar: participação nos estabelecimentos, na área e área média, segundo os grupos de área total (em ha) -2000

\begin{tabular}{|c|c|c|c|}
\hline $\begin{array}{c}\text { Grupos de Área } \\
\text { Total (ha) }\end{array}$ & $\begin{array}{c}\% \text { nos } \\
\text { Estabelecimentos }\end{array}$ & \% na Área & Área Média \\
\hline $\begin{array}{l}\text { Menos de } 5 \\
5 \text { a menos de } 20 \\
20 \text { a menos de } 50 \\
50 \text { a menos de } \\
100 \\
100 \text { ha a } 15 \\
\text { módulos regionais }\end{array}$ & $\begin{array}{c}39,8 \\
29,6 \\
17,2 \\
7,6 \\
5,9\end{array}$ & $\begin{array}{c}3,0 \\
12,2 \\
20,4 \\
19,7 \\
44,7\end{array}$ & $\begin{array}{c}1,9 \\
10,7 \\
31,0 \\
67,8 \\
198,0\end{array}$ \\
\hline $\begin{array}{l}\text { Área mé } \\
26,0\end{array}$ & dos & agricultores & familiares \\
\hline
\end{tabular}

<http://www.incra.gov.br/sade/doc/agriFam.htm>. Acesso em: 23 jun. 2005. Org. GOBBI, W. A. de O. $/ 2005$

O percentual do Valor Bruto da Produção - VBP - produzido pela agricultura familiar, quando consideradas algumas atividades, demonstra a sua 
importância em produtos destinados ao mercado interno e também entre os principais produtos que compõem a pauta de exportação agrícola brasileira.

A tabela 3 mostra que os agricultores familiares produzem $24 \%$ do VBP total da pecuária de corte, $52 \%$ da pecuária de leite, $58 \%$ dos suínos e $40 \%$ de aves e ovos produzidos. Em relação a algumas culturas temporárias e permanentes, a agricultura familiar produz $31 \%$ de arroz, $67 \%$ de feijão, $97 \%$ de fumo, $84 \%$ da mandioca, $49 \%$ do milho, $32 \%$ da soja e $25 \%$ do café.

Tabela 3 - Valor bruto da produção de produtos selecionados nos estabelecimentos familiares (\%) -2000

\begin{tabular}{l|c}
\multicolumn{1}{c|}{ Produto } & Participação no VBP Total \\
\hline Fumo & 97 \\
Mandioca & 84 \\
Feijão & 67 \\
Suínos & 58 \\
Pecuária leiteira & 52 \\
Milho & 49 \\
Aves / ovos & 40 \\
Soja & 32 \\
Arroz & 31 \\
Café & 25 \\
Pecuária de corte & 24 \\
\hline
\end{tabular}

Fonte: MDA/INCRA, 2000. Disponível em:

<http://www.incra.gov.br/sade/doc/agriFam.htm>. Acesso em: 23 jun. 2005.

Org. GOBBI, W. A. de O. $/ 2005$

O crescimento da renda desse segmento, por meio da conquista de mercado, traz impacto favorável, principalmente às regiões interioranas do país, onde exerce papel fundamental para o desenvolvimento social, evitando o êxodo rural e tornando-se instrumento de inclusão social, geração de trabalho e renda.

\section{A importância da agricultura familiar e da pecuária leiteira em Ituiutaba (MG)}

A agricultura familiar é uma categoria social que mostra uma característica histórica marcante, que é a sua marginalização ou exclusão de todo o processo de modernização da agricultura brasileira, conforme já analisado anteriormente. Essa marginalização tem origem no processo de 
reestruturação espacial e social que a modernização promoveu no Brasil. A marginalização espacial no sentido geográfico de ter criado áreas específicas modernizadas e produtivamente competitivas, promovendo uma grande diversidade regional, é considerada, por Graziano da Silva (1999), como uma das principais características da modernização brasileira. Social, no sentido de ter possibilitado um diferencial social entre os produtores, como os modernizados e não modernizados, excluindo do processo um grande número de agricultores, destacando entre eles o agricultor familiar.

Nesse processo, o Estado teve um papel fundamental, pois foi por meio da política agrícola, que promoveu a modernização da grande propriedade e garantiu sua reprodução em detrimento da agricultura familiar, que sempre ocupou um lugar secundário na sociedade brasileira (WANDERLEY, 1995). Nesse contexto, a agricultura familiar passou a sobreviver em um espaço social definido pós-modernização, por duas variáveis que condicionam a sua reprodução social: a primeira é o acesso restrito à propriedade da terra, e a segunda é a sua capacidade limitada de investimentos.

Tendo em vista esses problemas, os agricultores familiares buscam diversas estratégias para garantir sua sobrevivência dentro desse espaço social limitado, e a Comunidade da Canoa é uma delas, em que o agricultor organizado possui uma maior representatividade frente às suas reivindicações. O caso de Ituiutaba ilustra esta situação.

No município de Ituiutaba, o número significativo de unidades de produção familiar leva à necessidade de diferenciar as categorias familiar e patronal, visto que os dados utilizados, para compor o perfil da agricultura familiar no município, estão tabulados de acordo com essas categorias. Portanto, com o relatório elaborado pelo estudo FAO/INCRA (2000), podemos distinguir como unidades de produção familiar os estabelecimentos que possuam as seguintes características: a direção dos trabalhos do estabelecimento é exercida pelo produtor; o trabalho familiar é superior ao trabalho contratado; e o tamanho da propriedade é determinado pelo que a família pode explorar com base em seu próprio trabalho, associado à tecnologia de que dispõe ${ }^{3}$. Já a categoria patronal pode ser evidenciada pela 
utilização de mão-de-obra assalariada, incluindo trabalhadores permanentes e temporários, em que o trabalho familiar é marginal, limitando-se aos trabalhos de gestão e supervisão das atividades dentro da unidade de produção (FAO/INCRA, 2000).

Em Ituiutaba, a agricultura familiar apresenta um quadro diferente em relação à região Sudeste, onde o número de estabelecimentos e a área ocupada por este tipo de agricultor apresentam os maiores valores comparados com os dados nacionais.

Enquanto os agricultores familiares ocupam, no Brasil, um percentual de $30,5 \%$ da área total, o que corresponde a $85,2 \%$ do número total de estabelecimentos. No Sudeste, os números são, respectivamente, $29,2 \%$ e $75,3 \%$, sendo que, em Ituiutaba, os agricultores familiares ocupam $19,6 \%$ da área do município e $51 \%$ do número total de estabelecimentos (Gráfico 1).

\section{Gráfico 1 - Brasil/ Sudeste/ Ituiutaba (MG): agricultura familiar - número} de estabelecimentos e área em 1995/96 (\%)

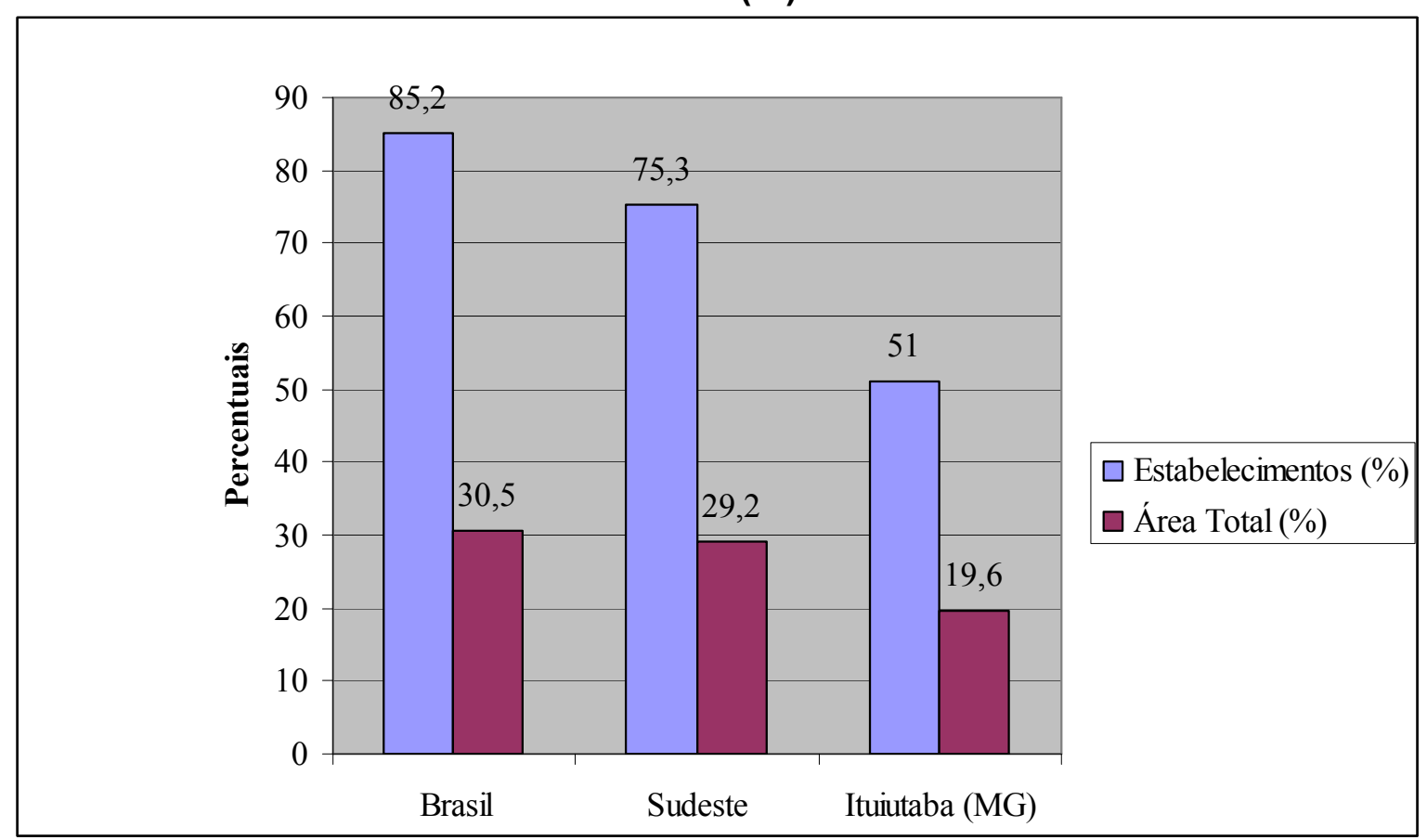

Fonte: IBGE - Censo Agropecuário 1995/96. Disponível em: <http://www.pronaf.gov.br.> Acesso em: 28 jun.2005. Org. GOBBI, W. A. de O. /2005

De acordo com os dados do Censo Agropecuário de 1995/96, Ituiutaba possui 641 estabelecimentos familiares, que correspondem a $19,6 \%$ da área total. A categoria patronal ocupa $80,4 \%$ da área total, com 606 
estabelecimentos, o que equivale a $48,2 \%$ do número total (Tabela 4). A área média das propriedades familiares no município é de, aproximadamente, 72 hectares, ficando acima da média para a Região Sudeste, que é de 29 hectares, e muito acima da média nacional, que é de 26 hectares. Com relação à categoria patronal, a área média, em Ituiutaba, é de 315 hectares; no Sudeste, esse número é de 222 ha; e, no Brasil, de 433 ha. Observamos que ocorre um equilíbrio entre o número de estabelecimentos familiares e patronais e que a área ocupada pelos estabelecimentos familiares é mais de quatro vezes menor que os estabelecimentos patronais (Tabela 4).

Tabela 4 - Ituiutaba (MG): número de estabelecimentos e área (total e média) por categorias familiar e patronal - 1995/96

\begin{tabular}{c|c|c|c}
\hline Categorias & $\begin{array}{c}\text { Número de } \\
\text { Estabelecimentos }\end{array}$ & Área Total (ha) & Área Média (ha) \\
\hline Familiar & 641 & 46.748 & 72,9 \\
Patronal & 606 & 190.935 & 315,1 \\
Outras $^{*}$ & 10 & 247 & 24,7 \\
\hline TOTAL & $\mathbf{1 . 2 5 7}$ & $\mathbf{2 3 7 . 9 3 0}$ & $\mathbf{1 8 9 , 3}$ \\
\hline
\end{tabular}

Fonte: IBGE - Censo Agropecuário (MG) 1995/96. Disponível em: <http://www.pronaf.gov.br>. Acesso em: 28 jun. 2005. Org. GOBBI, W. A. de O. $/ 2005$

* Outros - Instituições religiosas e públicas.

De acordo com a tabela 5, o número de estabelecimentos familiares encontra-se no grupo de área de 20 a 50 ha, totalizando 199 estabelecimentos (31\%), e, em seguida, vêm os estabelecimentos do grupo de área de mais de 100 ha, com 158 unidades de produção, representando 24,6\% do total de estabelecimentos. Esses dados mostram que mais de $50 \%$ dos estabelecimentos possui área entre 20 e mais de 100 hectares.

Tabela 5 - Ituiutaba (MG): número de estabelecimentos e área de acordo com grupos de área por categorias familiar e patronal - 1995/96

\begin{tabular}{|c|c|c|c|c|c|c|c|c|c|c|}
\hline \multirow[t]{2}{*}{ Categorias } & \multicolumn{2}{|c|}{$\begin{array}{c}\text { Menos de } \\
5 \text { ha }\end{array}$} & \multicolumn{2}{|c|}{$\begin{array}{c}\text { Entre } 5 \text { e } \\
20 \text { ha }\end{array}$} & \multicolumn{2}{|c|}{$\begin{array}{c}\text { Entre } 20 \text { e } \\
50 \text { há }\end{array}$} & \multicolumn{2}{|c|}{$\begin{array}{c}\text { Entre } 50 \text { e } \\
100 \text { ha }\end{array}$} & \multicolumn{2}{|c|}{ Mais de 100 ha } \\
\hline & N. ${ }^{\circ}$ & Área & $\mathbf{N}^{0}$ & Área & N. ${ }^{0}$ & Área & N. ${ }^{0}$ & Área & N. ${ }^{\circ}$ & Área \\
\hline Fan & 43 & 134 & 104 & 1.375 & 199 & 6.936 & 137 & 10.070 & 158 & 28.234 \\
\hline Patronal & 10 & 30 & 24 & 68 & 68 & 2.358 & 93 & 7.081 & 411 & 181.149 \\
\hline
\end{tabular}


A condição do produtor centraliza-se na de proprietário, tanto para a categoria familiar como para a patronal, correspondendo a 83,6\% e 90,2\%, respectivamente, dos estabelecimentos totais (Tabela 6 ).

Tabela 6 - Ituiutaba (MG): estabelecimentos e área segundo a condição do produtor por categoria familiar e patronal (n. ${ }^{\circ}$ total) - 1995/96

\begin{tabular}{|c|c|c|c|c|c|c|c|c|}
\hline \multirow[t]{2}{*}{ Categorias } & \multicolumn{2}{|c|}{ Proprietário } & \multicolumn{2}{|c|}{ Arrendatário } & \multicolumn{2}{|c|}{ Parceiro } & \multicolumn{2}{|c|}{ Ocupante } \\
\hline & N. ${ }^{0}$ & ha & N. ${ }^{0}$ & ha & $\mathbf{N} .^{0}$ & ha & N. ${ }^{0}$ & ha \\
\hline TOTAL & 1.086 & 219.112 & 91 & 9.396 & 5 & 1.026 & 75 & 8.394 \\
\hline Familiar & 536 & 40.217 & 58 & 3.546 & 2 & 165 & 45 & 2.819 \\
\hline Patronal & 547 & 178.723 & 33 & 5.849 & 3 & 861 & 23 & 5.500 \\
\hline
\end{tabular}

Org. GOBBI, W. A. de O. $/ 2005$

Do total do pessoal ocupado na agricultura em Ituiutaba (Tabela 7), a agricultura familiar é responsável pela absorção da maioria dos trabalhadores $(74,6 \%)$, enquanto a categoria patronal emprega $25,4 \%$ do pessoal. A agricultura familiar ocupa 1.863 trabalhadores, dos quais $81,4 \%$ correspondem à mão-de-obra dos membros da família, sendo o restante dividido entre parceiros $(11,5 \%)$, empregados permanentes $(6,1 \%)$ e outra condição $(1,0 \%)$.

Tabela 7 - Ituiutaba (MG): pessoal ocupado por categoria familiar e patronal ( . $^{\circ}$ total) - 1995/96

\begin{tabular}{c|c|c|c|c|c|c|l}
\hline $\begin{array}{c}\text { Categoria } \\
\mathbf{s}\end{array}$ & Total & $\begin{array}{c}\text { Familia } \\
\text { r maior } \\
\text { de 14 } \\
\text { anos } \\
\left(\mathrm{n} .^{\circ}\right. \\
\text { Total })\end{array}$ & $\begin{array}{c}\text { Familiar } \\
\text { menor } \\
\text { de 14 } \\
\text { anos }\left(\mathrm{n} .^{\circ}\right. \\
\text { Total) }\end{array}$ & $\begin{array}{c}\text { Parceiro } \\
\mathbf{s}\left(\mathrm{n} .^{\circ}\right. \\
\text { Total) }\end{array}$ & $\begin{array}{c}\text { Empregados } \\
\text { Permanente } \\
\mathbf{s}\left(\mathrm{n} .^{\circ} \text { Total) }\right.\end{array}$ & $\begin{array}{c}\text { Empregado } \\
\text { s } \\
\text { Temporário } \\
\text { s (n. }{ }^{\circ} \text { Total) }\end{array}$ & $\begin{array}{l}\text { Outra } \\
\text { Condição } \\
\text { (n. } .^{\circ} \text { Total) }\end{array}$ \\
\hline Familiar & 1.863 & 1.390 & 123 & 214 & 114 & 1 & 18 \\
\hline Patronal & 2.496 & 745 & 10 & 1.312 & 333 & 32 & 64 \\
\hline
\end{tabular}

Fonte: IBGE - Censo Agropecuário (MG) 1995/96. Disponível em: <http://www.pronaf.gov.br>. Acesso em: 28 jun. 2005.

Org. GOBBI, W. A. de O. $/ 2005$

A combinação de mão-de-obra familiar com empregados permanentes e temporários (Tabela 8) corresponde a uma parcela insignificante do total de estabelecimentos (5,4\%). O trabalho na agricultura é, basicamente, praticado pela mão-de-obra familiar $(46,6 \%)$ e pela conciliação da mão-de-obra familiar com as demais combinações $(31,4 \%)$. 
Tabela 8 - Ituiutaba (MG): mão-de-obra na agricultura familiar por tipo e combinação em relação aos estabelecimentos (\%) e área (\%) - 1995/96

\begin{tabular}{l|c|c|c|c}
\hline \multirow{2}{*}{ Mão-de-obra } & \multicolumn{2}{|c|}{ Estabelecimentos } & \multicolumn{2}{c}{ Área Total } \\
\cline { 2 - 5 } & $\mathbf{n} .^{\circ}$ & $\mathbf{\%}$ & ha & \% \\
\hline \multicolumn{1}{c|}{ Total familiar } & $\mathbf{6 4 1}$ & $\mathbf{1 0 0}$ & $\mathbf{4 6 . 7 4 8}$ & $\mathbf{1 0 0}$ \\
\hline $\begin{array}{l}\text { Só mão-de-obra familiar } \\
\text { Mão-de-obra familiar e } \\
\text { temporária }\end{array}$ & 299 & $\mathbf{4 6 , 6}$ & 17.402 & 37,2 \\
\hline $\begin{array}{l}\text { Mão-de-obra fam., temp. e } \\
\text { permanente }\end{array}$ & 6 & $\mathbf{2 , 5}$ & 1.806 & 3,9 \\
\hline $\begin{array}{l}\text { Mão-de-obra fam. e } \\
\text { emprego máquinas }\end{array}$ & 119 & 18,6 & 712 & 1,5 \\
\hline $\begin{array}{l}\text { Mão-de-obra fam. e demais } \\
\text { combinações }\end{array}$ & 201 & 31,4 & 18.906 & 16,9 \\
\hline
\end{tabular}

Fonte: IBGE - Censo Agropecuário (MG) 1995/96. Disponível em: <http://www.pronaf.gov.br>. Acesso em: 28 jun. 2005. Org. GOBBI, W. A. de O. $/ 2005$

É importante salientar que, ao comparar os dados do município de Ituiutaba com os da região Sudeste, pode-se notar que os agricultores familiares de Ituiutaba têm maior acesso à tecnologia e assistência técnica que a média geral da região (Tabela 9).

Tabela 9 - Região Sudeste e Ituiutaba (MG): estabelecimentos familiares com acesso à força de trabalho, tecnologia e assistência técnica (\%) $1995 / 96$

\begin{tabular}{l|c|c|c|c|c}
\hline \multirow{2}{*}{ Local } & \multicolumn{5}{|c}{ Estabelecimentos } \\
\cline { 2 - 7 } & $\begin{array}{c}\text { Só força } \\
\text { Manual } \\
(\%)\end{array}$ & $\begin{array}{c}\text { Uso da } \\
\text { Força } \\
\text { Animal ou } \\
\text { Mecânica } \\
(\%)\end{array}$ & $\begin{array}{c}\text { Energia } \\
\text { Elétrica } \\
(\%)\end{array}$ & $\begin{array}{c}\text { Uso de } \\
\text { Adubos e } \\
\text { Corretivos } \\
\%)\end{array}$ & $\begin{array}{c}\text { Assistência } \\
\text { Técnica } \\
(\%)\end{array}$ \\
\hline Sudeste & 42,2 & 57,8 & 56,2 & 60,6 & 22,7 \\
\hline Ituiutaba & 25,9 & 74,1 & 78,0 & 73,5 & 36,0 \\
\hline Fonte: IBGE - Censo & Agropecuário $(\mathrm{MG})$ & $1995 / 96 . \quad$ Disponível em:
\end{tabular}

<http://www.pronaf.gov.br>. Acesso em: 28 jun. 2005.

Org. GOBBI, W. A. de O. $/ 2005$ 
Atualmente (2005), uma das atividades econômicas preponderantes do município de Ituiutaba é a pecuária leiteira, exercida, basicamente, por pequenos produtores, com mão-de-obra centrada no trabalho familiar. Essa atividade ganhou força na década de 1970, quando Ituiutaba ampliou o rebanho bovino e, conseqüentemente, a produção leiteira.

Podemos observar, na tabela 10, que a produção de leite e carne em Ituiutaba, no ano de 2001, correspondeu a 83.673,6 mil litros de leite e $8.728,7$ toneladas de carne, com valores de $40.163,32$ e $29.677,75$ mil reais, respectivamente.

Tabela 10 - Ituiutaba (MG): produção e valor da pecuária - 2001

\begin{tabular}{l|c|c|c}
\hline Produtos & \multicolumn{2}{|c|}{ Produção } & Valor da produção \\
& (mil l) & (t) & $40.163,32$ \\
\hline Leite & $83.673,6$ & --- & $29.677,75$ \\
\hline Carne & --- & $8.728,7$ & \\
\hline
\end{tabular}

Fonte: EMATER-MG(2003)

W.A. de $0 . / 2003$

Org.GOBBI,

O total do rebanho bovino é de 199.834 cabeças. Com relação à mãode-obra ocupada, 1.482 pessoas trabalham na atividade leiteira e 471 pessoas são empregadas na atividades relacionadas ao rebanho de corte (EMATER, 2003).

Com relação ao número de vacas ordenhadas e quantidade de leite, em Ituiutaba (Tabela 11), houve um aumento significativo de 1970 (13.252 vacas/ 5.434 mil litros) para 2003 (29.900 vacas ordenhadas/ 28.600 mil litros). Houve, também, um aumento na área de pastagem, principalmente entre os anos de 1970 (163.265 ha) a 1985 (203.782 ha), em decorrência da abertura dos cerrados, o que permitiu o estabelecimento de pastagens de capins do gênero Brachiaria e a expansão da pecuária. Em Ituiutaba, a área destinada às culturas de arroz, milho e algodão até o final da década de 1960, foi, progressivamente, ocupada por pastagens, a partir da década de 1970.

Tabela 11 - Ituiutaba (MG): vacas ordenhadas (n. ${ }^{\circ}$ ), produção de leite (I) e área de pastagem (ha) - 1970 a 2003

\begin{tabular}{l|l|l|l}
\hline Anos & $\begin{array}{l}\text { N. }{ }^{\circ} \text { de vacas } \\
\text { ordenhadas }\end{array}$ & Leite (mil litros) & Área de pastagem (ha) \\
\hline
\end{tabular}

ISSN 1981-9021 - Geo UERJ - Ano 11, v.2, n.19, $1^{\circ}$ semestre de 2009. P. 79-110 www.geouerj.uerj.br/ojs 


\begin{tabular}{l|c|c|c}
\hline 1970 & 13.252 & 5.434 & 163.265 \\
1975 & 15.040 & 6.166 & $\left({ }^{*}\right)--$ \\
1980 & 28.693 & 20.807 & 168.401 \\
1985 & 26.667 & 25.436 & 203.782 \\
$1995 / 96$ & 27.742 & 30.172 & 145.464 \\
2003 & 29.900 & 28.600 & 174.414 \\
\hline
\end{tabular}

Fonte: IBGE - Censo Agropecuário (MG) 1970, 1975, 1980 1985, 1990, 1995/96, 2000 e 2003. Disponível em: www.ibge.gov.br. Acesso em: 14 nov. 2005. *(---) Dado não encontrado no ano de 1975. Org. GOBBI, W. A. de O. /2005.

$\mathrm{Na}$ área em questão, a pecuária é uma atividade praticada por pequenos, médios e grandes produtores, atendendo à finalidade de corte e, principalmente, leite pelos pequenos e médios. Porém, mesmo com o preço, tanto da carne quanto do leite, não correspondendo ao custo de produção, tem ocorrido a expansão da pecuária que, para Graziano da Silva (1978, p.91), "está bastante vinculada à afirmação do modo capitalista de produção da agricultura."

O referido autor apontou quatro fatores que contribuíram para explicar a expansão da atividade pecuária no Brasil. Em primeiro lugar, os investimentos em pecuária (compra de terras de pastos naturais e rebanhos) asseguram, por si mesmos, a "valorização" do capital investido, num período de inflação alta, como nas décadas de 1970 e 1980. Dessa forma, tanto o rebanho quanto as terras passaram a ser transformadas em dinheiro a qualquer momento. Em segundo lugar, a evolução dos preços do boi para o corte, na década de 1970, foi favorável e constante ao mercado. Em terceiro lugar, o custeio intensivo da pecuária esteve em consonância com o absenteísmo do grande proprietário. $O$ gado alimentava-se do pasto natural e exigia baixo nível tecnológico (poucas vacinações e sal grosso). Por último, a pecuária de corte era uma atividade de poucos riscos, exigindo poucos investimentos (GRAZIANO DA SILVA, 1978).

Assim, a pecuária regional, que era praticada como meio de subsistência paralelo às atividades de agricultura, ganhou, nesse sentido, mais incentivo para tornar-se a atividade principal, e os campos abertos para cultivo passaram a ser transformados em pastos.

De acordo com Duarte (2001), como incentivo à pecuária, alguns projetos beneficiaram fazendeiros na Microrregião de Ituiutaba, destacando o 
Conselho de Desenvolvimento da Pecuária (CONDEPE) e o programa de Desenvolvimento da Pecuária do Cerrado (PROPEC). A introdução do capim Brachiara nos cerrados foi um incentivo na alimentação do gado. Desenvolvida por técnicos da Empresa Brasileira de Pesquisa Agropecuária - EMBRAPA -, que buscavam uma espécie de gramínea para responder à situação com uma alta produção em massa para sustentar os animais e os alimentasse tanto no período das águas quanto no da seca. Na visão do Sr. Walter ${ }^{4}$,

"para a produção do leite, a brachiara, não é a gramínea mais recomendada, mas na região, ela é atualmente (década de 1990/2000), a gramínea predominante, justamente pela sua duração e a sua resistência ao clima".

Após a década de 1970/80, os municípios da Microrregião de Ituiutaba passaram a investir numa economia voltada para o setor leiteiro e de carnes. Os serviços foram adaptados em função desse novo rural, e técnicas e instituições de pesquisa ganharam relevância, tais como a EMBRAPA, Empresa de Assistência Técnica e Extensão Rural de Minas Gerais - EMATER -, Universidade do Estado de Minas Gerais - UEMG -, entre outros. Entretanto, a forte inclinação do município para a pecuáriam, após 1970, reduziu a produção agrícola, tornando-se menos significativa, de acordo com a tabela 12.

O arroz e o algodão representam muito pouco do que já simbolizaram para a Microrregião de Ituiutaba, a cana-de-açúcar tem crescido devido à instalação de duas usinas de álcool, sendo uma no município de Canápolis e outra no município de Capinópolis. Estes dois municípios são vizinhos de Ituiutaba, e sua produção serve de matéria-prima para as usinas. Portanto, após a década de 1990, os grãos (milho, soja) e o algodão são os cultivos mais plantados pelos produtores, principalmente pelos arrendatários (Tabela 12).

De acordo com a tabela 12, a produção leiteira praticamente triplicou, e a de carne dobrou entre 1970 e 1980, apresentando, posteriormente, taxas reduzidas de crescimento, posto que já havia se consolidado na Microrregião de Ituiutaba. 
Em 1975, conforme já destacado, ocorreu a instalação de uma fábrica de leite em pó da Nestlé, responsável, mais tarde, por mudanças relevantes nesse setor envolvendo os produtores regionais.

Sua presença, passa a ser a causa e ao mesmo tempo que a conseqüência da euforia leiteira regional. Significou para os fazendeiros um grande incentivo e a certeza de um comprador para o leite, contribuindo decididamente para a especialização da pecuária regional. (OLIVEIRA, 2003, p. 87).

A mudança de atividade (lavouras de arroz, milho, algodão...) para pecuária de leite gerou novas relações, que são visualizadas no campo e no urbano de Ituiutaba. A instalação da Nestlé passou a reestruturar as relações comerciais, econômicas, sociais e políticas no município. Sua presença gerou a necessidade entre os fazendeiros de se adaptarem ao sistema tecnológico que a Nestlé exigiu, "tudo por uma melhor qualidade do produto". A instalação passara a ser a causa e conseqüência da especialização leiteira na microrregião de Ituiutaba, e o seu nome a ter um importante significado para a cidade. 
Tabela 12 - Ituiutaba (MG): produção agropecuária - 1970/1980/1991/2002

\begin{tabular}{|c|c|c|c|c|c|c|c|c|c|c|c|c|c|c|}
\hline \multirow[t]{2}{*}{ Ano } & \multicolumn{11}{|c|}{ Produção Agrícola (ha) } & \multicolumn{3}{|c|}{ Produção Pecuária } \\
\hline & $\begin{array}{c}\text { Algodã } \\
0\end{array}$ & Arroz & $\begin{array}{c}\text { Bana } \\
\text { na }\end{array}$ & $\begin{array}{l}\text { Cana- } \\
\text { de- } \\
\text { açúca } \\
\text { r }\end{array}$ & Feijão & $\begin{array}{l}\text { Laranj } \\
\quad a\end{array}$ & $\begin{array}{c}\text { Mandio } \\
\text { ca }\end{array}$ & Milho & Soja & Sorgo & TOTAL & $\begin{array}{c}\text { Bovinos } \\
\text { (N. }{ }^{\circ} \text { de } \\
\text { cabeça } \\
\text { s) }\end{array}$ & $\begin{array}{l}\text { Leite }(\mathrm{L}) \\
\text { In natura }\end{array}$ & $\begin{array}{c}\text { Área de } \\
\text { pastagem } \\
\text { (ha) }\end{array}$ \\
\hline $\begin{array}{l}197 \\
0 \\
198 \\
0 \\
199 \\
1 \\
200 \\
2\end{array}$ & $\begin{array}{c}2.449 \\
561 \\
2.000 \\
1.000\end{array}$ & $\begin{array}{c}19.52 \\
6 \\
8.615 \\
3.430 \\
250\end{array}$ & $\begin{array}{l}24 \\
33 \\
45 \\
---\end{array}$ & $\begin{array}{c}63 \\
144 \\
300 \\
1.000\end{array}$ & $\begin{array}{c}1.521 \\
33 \\
110 \\
---\end{array}$ & $\begin{array}{c}10 \\
35 \\
75 \\
560\end{array}$ & $\begin{array}{c}7 \\
122 \\
350 \\
500\end{array}$ & $\begin{array}{c}12.23 \\
6 \\
10.62 \\
6 \\
12.00 \\
0 \\
6.000\end{array}$ & $\begin{array}{c}41 \\
2.096 \\
2.500 \\
12.00 \\
0\end{array}$ & $\begin{array}{c}--- \\
30 \\
--- \\
1.000\end{array}$ & $\begin{array}{l}35.836 \\
19.841 \\
20.810 \\
22.310\end{array}$ & $\begin{array}{c}83.972 \\
166.88 \\
6 \\
178.22 \\
2 \\
220.00 \\
0\end{array}$ & $\begin{array}{c}5.430 .00 \\
0 \\
20.807 .0 \\
00 \\
26.253 .0 \\
00 \\
28.000 .0 \\
00\end{array}$ & $\begin{array}{l}163.265 \\
168.401 \\
145.464 \\
174.414\end{array}$ \\
\hline
\end{tabular}

Fonte: IBGE - Censo Agropecuário (MG) 1970, 1980, 1991 e 2002. Disponível em: www.ibge.gov.br. Acesso em: 14 nov. 2005. Org. GOBBI, W. A. de O. $/ 2005$.

Questões, como a alta produtividade leiteira de Minas Gerais e da tradicional bacia leiteira do Triângulo Mineiro/Alto Paranaíba, foram levadas em conta, bem como a proximidade com o Estado de Goiás e rodovias que se direcionam a São Paulo. A Nestlé também realizou uma pesquisa em busca de condições favoráveis à sua instalação, que exigia um mercado regional fornecedor e consumidor de sua matéria-prima (leite), além de infra-estrutura de circulação e telecomunicação. Hoje (2005), uma cooperativa (Coopontal) e outras empresas (laticínios Canto de Minas, Guadalupe) de menor porte também dividem o mesmo espaço em Ituiutaba no ramo de laticínios, além de frigoríficos que absorvem a produção bovina e suína de corte. Para Duarte (2001), a pecuária de corte é bastante representativa para o município, bem como para a região do Triângulo Mineiro/Alto Paranaíba. O Frigorífico Bertin, instalado na cidade, destaca-se como um dos maiores exportadores de 
carne do país. Quanto à pecuária leiteira, a fábrica de leite em pó da Nestlé e o Laticínio Canto de Minas estão capacitados a processar até 1.350 .000 e 50.000 litros de leite/dia, respectivamente. 


\section{Considerações Finais}

Os principais pontos, discutidos constantemente neste trabalho, ressaltam algumas peculiaridades da atividade leiteira que a tornam especial no contexto da produção agrícola. O leite tem sua importância ressaltada por representar a garantia de obtenção de uma renda ao final de cada mês, por não estar tão suscetível às mudanças climáticas (fazendo com que essa seja uma atividade mais segura). Além do mais, na maioria das propriedades do município de Ituiutaba, tem sido mantida a produção leiteira com a mão-deobra familiar, evitando, assim, que se gaste com a contratação de mão-deobra. Por menor que seja a produção, é possível obter uma remuneração mínima que possibilite a sobrevivência dos produtores. Esses produtores estão acostumados a lidar com restrições e não abandonarão a atividade facilmente.

Como se trata de uma realidade que comporta produtores com diversas peculiaridades e, conseqüentemente, com necessidades distintas, não é possível estabelecer regras que possam favorecer todos os produtores de leite. É importante destacar que, se não há uma solução única para os problemas dos pequenos produtores, há algumas medidas que poderão apaziguar e trazer benefícios para a grande maioria. Medidas que promovam a elevação geral de renda, a redução dos juros, ir em busca de maior competitividade, o melhoramento da infra-estrutura e a formação de formas associativas. Com certeza, se houver vontade e interesse em fortalecer esses produtores para atuarem em um novo ambiente, essa oportunidade não será desperdiçada. Os produtores de leite estão carentes e sedentos de alternativas que tornem viável a sua permanência na atividade leiteira. Além disso, não se trata só de uma necessidade econômica, mas também social.

\section{Notas}

${ }^{1}$ Essa discussão é parte da dissertação de mestrado "A pecuária leiteira na comunidade da Canoa - Ituiutaba (MG): persistência e resistência" (2006) sob a orientação da profa. Dra. Vera Lúcia Salazar Pessôa - PPGG/IG/UFU.

\footnotetext{
${ }^{2}$ Além desse critério, foi utilizada uma metodologia específica para estabelecer o tamanho médio das unidades familiares. Para mais detalhes, ver FAO/INCRA, 2000, p.11.
} 
${ }^{3}$ Para mais detalhes, ver FAO/INCRA, 2000, p.11.

${ }^{4}$ Entrevista concedida pelo Sr. Walter Eurípedes de Oliveira - pequeno produtor rural de leite em Ituiutaba - em fevereiro de 2005.

\section{Referências}

ABRAMOVAY, R. Funções e medidas da ruralidade no desenvolvimento contemporâneo. Rio de Janeiro: IPEA, 2000.

AZEVEDO, F. F. Seridó Potiguar: Dinâmica socioespacial e organização do espaço agrário regional. Uberlândia: Composer, 2005.

Caracterização da agricultura familiar no Brasil. Disponível em: <http://www.seag.es.gov.br/familiar_caracterização.htm>. Acesso em: 20 jun. 2005.

CAUME. D. J. A agricultura familiar no estado de Goiás. Goiânia: UFG, 1997.

CHAYANOV, A. V. La organización de la unidad económica campesina. Tradução de Rosa María Rússovich. Buenos Aires: Nueva Visión, 1974. 342p. Cap. 2. p. 69-95.

DUARTE, M. Q. S. Raízes rurais na vivência urbana: persistências, desistências, recriações. Ituiutaba - 1970 - 1985. 2001. 150f. Dissertação (Mestrado em História) - Instituto de História, Universidade Federal de Uberlândia, Uberlândia, 2001.

FAO/INCRA. Novo retrato da agricultura familiar - 0 Brasil redescoberto. Brasília: 2000. Projeto de cooperação Técnica INCRA/FAO. p. 74.

A agricultura familiar no Brasil. (agricultura familiar e sistemas de produção). Brasília: 2000. Projeto: UTF/BRA/051/BRA. p. 16-27.

GRAZIANO DA SILVA, J. Estrutura agrária e produção de subsistência na agricultura brasileira. São Paulo: HUCITEC, 1978.

O que é questão agrária. 2. ed. São Paulo: Brasiliense, 1996.

A modernização conservadora dos anos 70. In: ___ Tecnologia e agricultura familiar. Porto Alegre: Editora da Universidade - UFRGS, 1999. p. $87-135$.

KAGEYAMA, A. et. al. O novo padrão agrícola brasileiro: do complexo rural aos complexos agroindustriais. In: DELGADO, G. C.; GASQUES, J. G.; VILLA 
VERDE, C. M. (Org.). Agricultura e políticas públicas. Brasília: IPEA, n. 127, 1990. p. $113-253$.

LAMARCHE, H. (Coord.). As questões em debate. In:

A agricultura familiar: do mito à realidade. Tradução de Frédéric Bazin. Campinas: Editora da Unicamp, 1998. p. 17 - 45. v. II.

OLIVEIRA, B. S. de. Ituiutaba (MG) na rede urbana Tijucana: (re) configuração sócio-espaciais no período de 1950 a 2000. 2003. $205 f$. Dissertação (Mestrado em Geografia) - Instituto de Geografia, Universidade Federal de Uberlândia, Uberlândia, 2003.

PEIXOTO, S. E. A pequena produção agrícola: algumas questões atuais. Revista Bahia Agrícola, Salvador, v. 2, n. 3, p. 1-6, nov., 1998.

PESSOA, J. de M. A revanche camponesa. Goiânia: UFG, 1999.

PETRONE, M. T. S. O imigrante e a pequena propriedade (1824 - 1930). São Paulo: Brasiliense. 1982.

PRADO JÚNIOR, C. Vida material: pecuária. In: Formação do Brasil Contemporâneo. 17.ed. São Paulo: Brasiliense, 1981. p. 186-210.

ROMEIRO, A. R. A difusão mundial do modelo Euro-Americano. In: Meio ambiente e dinâmica de inovações na agricultura. São Paulo: Annablume: FAPESP, 1998. p. $95-122$.

SORJ, B. Estado e classes sociais na agricultura brasileira. Rio de Janeiro: Guanabara, 1986.

WANDERLEY, M. de N. B. A agricultura familiar no Brasil: um espaço em construção. 1995. mimeo.

. O "lugar" dos rurais: o meio rural no Brasil moderno. In: CONGRESSO BRASILEIRO DE ECONOMIA E SOCIOLOGIA RURAL, 35., 1997, Rio Grande do Norte. Anais... Rio Grande do Norte. p. 90-113.

Raízes históricas do campesinato brasileiro. In: TEDESCO, J. C. (Org.). Agricultura familiar: realidades e perspectivas. Passo Fundo: UPF, 1999. p. $21-55$.

Artigo encaminhado para publicação em julho de 2009.

Artigo aceito para publicação em agosto de 2009. 